\title{
Longitudinal cognitive development of children born to mothers with opioid and polysubstance use
}

\author{
Egil Nygaard ${ }^{1,2}$, Vibeke Moe ${ }^{2,3}$, Kari Slinning ${ }^{2,3}$ and Kristine B. Walhovd ${ }^{1,4}$
}

BACKGROUND: Previous studies indicate an increased risk for neuropsychological difficulties in young children prenatally exposed to opioids and polysubstances, but longitudinal information is scarce. The present longitudinal study investigated whether these waned, persisted, or increased over time.

METHODS: The cognitive functioning of 72 children with prenatal opioid and polysubstance exposure and 58 children without any established prenatal risk was assessed at 1, 2, 3, $4 \frac{1}{2}$, and $8 \frac{1}{2} \mathrm{y}$.

RESULTS: The exposed boys had significantly and stably lower levels of cognitive functioning than the control group, whereas there were increasing differences over time for the girls. The exposed group had significantly lower IQ scores than the control group on Wechsler Intelligence Scale for Children-Revised at $8 \frac{1}{2}$ y after controlling for earlier cognitive abilities, and for children who were permanently placed in adoptive/foster homes before 1 y of age and whose mothers used heroin as their main drug during pregnancy $(B=17.04$, 95\% Cl 8.69-25.38, $P<0.001)$.

CONCLUSION: While effects of prenatal substance exposure cannot be isolated, group effects on cognition rather increased than waned over time, even in adoptive/foster children with minimal postnatal risk.

C hildren prenatally exposed to opioids and polysubstances are at increased risk for neuropsychological dysfunction (1-4). Maternal opioid use and neonatal abstinence syndrome have increased the past 15 y $(5,6)$, and maintenance therapy has been the recommended treatment for opioidaddicted pregnant women for decades (7). Neurocognitive and behavioral consequences of human prenatal exposure to alcohol and cocaine have been well documented $(8,9)$. However, there have been relatively few studies of opioid and polysubstance exposure $(2,10)$. Importantly, the fate of these children over time is unknown. The present study investigates which of three possible developmental trajectories characterize these children: Do they catch up, remain at disadvantage or do they proceed to function even more poorly than peers over time?
The studies that have been conducted on children prenatally exposed to opioids and polysubstance abuse have virtually exclusively focused on infancy and early childhood. Most have found that infants born to mothers with opioid and polysubstance-abuse during pregnancy show lower cognitive performance and affect regulation than nonexposed infants (2). Opioid and polysubstance-exposed children have also been found to have smaller neuroanatomical volumes and indices of lesser maturation of neural tracts than controls (11-14). Animal studies have found prenatal opioid exposure to have teratogenic effects, including disruption of neuronal migration and/or cell survival $(15,16)$, decrease of dendrite length and branch number in pyramidal neurons in the somatosensory cortex (17) and disruptions to several neurotransmitter systems (18).

Some studies suggest that differences in cognitive abilities may be due to concordant factors, such as low birth weight and a nonoptimal caregiving environment (19). Thus, the increased risk possibly stem from a combination of biological vulnerabilities and postnatal environmental correlates related to the mothers' substance abuse that interact over time. However, studies suggest that infants and children prenatally exposed to opioid and polysubstance abuse who have been adopted at an early age have lower mental abilities $(3,20)$ and more signs of attention deficits than control groups $(3,21)$.

There may also be gender-dependent effects of prenatal exposure to opioids and poly-substance use, as have been found for prenatal exposure to cocaine (22). Whereas some have found prenatally opioid-exposed boys to be more vulnerable than girls $(20,23)$, others have not found any gender differences (e.g., ref. (24)). Thus, the question concerning gender specific vulnerability for opioid and polysubstance exposure is unsettled.

It has been postulated that optimization of the postnatal environment may compensate for the biological vulnerability of these children $(25,26)$. The children may for example have a positive trajectory over time if they were brought up in good foster or adoptive homes which compensated for their prenatal vulnerabilities. However, the few longitudinal studies of children exposed to opioids and polysubstances prenatally 
rather indicate either a similarly shaped trajectory as control group $(19,20,24,27)$, or a tendency for more clearly manifested psychomotor and cognitive difficulties through infancy, early childhood $(26,28)$, and adolescence $(3)$, even when adopted at an early age.

The biological vulnerabilities of prenatally drug-exposed children may influence early cognitive abilities which again are highly related to later cognitive abilities. However, the prenatal vulnerabilities may also have a continuous direct effect on the ability to acquire new skills. Effects of maternal opioid use on complex cognition and self-regulation, such as executive functions, can only be observed when these behaviors develop, i.e., during school age years and beyond.

The present study investigates cognitive differences over time between children with prenatal heroin and polysubstance exposure and children without any known prenatal drug exposure. One common confounding factor in clinical studies of prenatal exposure to illegal drugs, as also in the present study, is that the mothers using opioids, whether through prescribed maintenance therapy or illegally, very often also use other legal

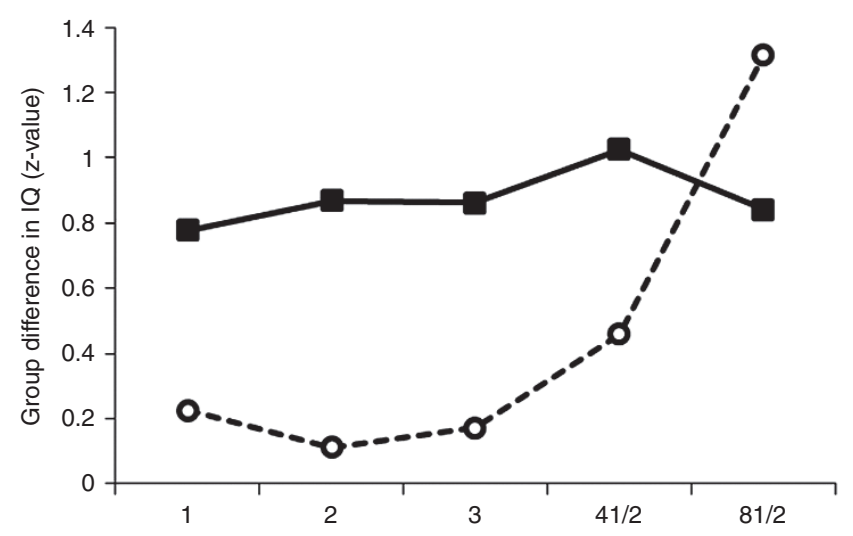

Figure 1. Differences in cognitive abilities between the opioid and polysubstance-exposed group and the control group across time divided by gender (- - O- - Girls, $-\square-$ Boys). All scores are differences between groups in standardized (Z) scores (SD). Values above zero indicate higher cognitive scores in the control group than in the drug-exposed group. Measure and sample size varies across time (Table 1). and illegal drugs (29), The most common drug of choice in the present study, besides tobacco, was heroin, and many of the mothers used multiple drugs. Because there is a lack of knowledge about children born to mothers using heroin during pregnancy, the results are shown both for all participants, and for the subgroup of heroin-exposed children. It is however important to remember that all mothers had polysubstanceuse, also within this subgroup.

Based on empirical findings on early development, we hypothesize that the known difference in cognitive abilities between opioid and polysubstance-exposed children and controls is not reduced over time from 1 y until $8 \frac{1}{2}$ y of age and may even be augmented. We also hypothesize that group differences at $81 / 2$ may be found even after taking into account earlier cognitive abilities. This would indicate processes influencing the cognitive abilities of the exposed children negatively between $4 \frac{1}{2}$ and $8 \frac{1}{2}$ y of age.

\section{RESULTS}

\section{Cognitive Differences Across Ages 1 to $81 \frac{1}{2}$ y}

The exposed group had significantly lower cognitive scores at all time points than the control group $\left(\mathrm{M}_{\text {diff } 1 \mathrm{y}}=6.5,95 \% \mathrm{CI}\right.$ $2.2-10.8 ; \mathrm{M}_{\text {diff } 2 \mathrm{y}}=8.0,95 \% \mathrm{CI} 2.8-13.2 ; \mathrm{M}_{\text {diff } 3 \mathrm{y}}=6.8,95 \% \mathrm{CI}$ $2.8-10.9 ; M_{\text {diff } 4 \frac{1 / 2 y}{y}}=12.0,95 \%$ CI $7.0-16.9 ; M_{\text {diff } 8 \frac{1}{2} y}=18.3,95 \%$ CI 12.3-24.2, all with $P<0.01)$. However, there were marked sex differences (Figure 1). The exposed boys scored significantly lower than the boys in the control group on all assessments (Table 1). The exposed girls also obtained lower scores than the control group, but this difference was only significant on the last assessment. The group differences for the girls at last assessment and for the boys at the last two assessments were significant also after controlling for socioeconomic status (SES), gestational age and birth weight in a mixed effect model including the interaction effect between group and time (Table 1).

Mixed effect analyses based on standardized scores were conducted to investigate whether the difference in cognitive scores between the groups changed significantly over time for the whole group. The models controlled for gender, SES,

Table 1. Cognitive abilities across ages divided by group and gender

\begin{tabular}{|c|c|c|c|c|c|c|c|c|c|c|c|c|c|c|}
\hline & \multicolumn{7}{|c|}{ Girls } & \multicolumn{7}{|c|}{ Boys } \\
\hline & \multicolumn{2}{|c|}{ Exposed group } & \multicolumn{2}{|c|}{ Control group } & \multicolumn{3}{|c|}{ Group diff. } & \multicolumn{2}{|c|}{ Exposed group } & \multicolumn{2}{|c|}{ Control group } & \multicolumn{3}{|c|}{ Group diff. } \\
\hline & \multirow[b]{2}{*}{$n$} & \multirow[b]{2}{*}{ Mean (SD) } & \multirow[b]{2}{*}{$n$} & \multirow[b]{2}{*}{ Mean (SD) } & \multicolumn{2}{|c|}{$95 \% \mathrm{Cl}$} & \multirow[b]{2}{*}{$P$} & \multirow[b]{2}{*}{$n$} & \multirow[b]{2}{*}{ Mean (SD) } & \multirow[b]{2}{*}{$n$} & \multirow[b]{2}{*}{ Mean (SD) } & \multicolumn{2}{|c|}{$95 \% \mathrm{Cl}$} & \multirow[b]{2}{*}{$P$} \\
\hline & & & & & Lower & Upper & & & & & & Lower & Upper & \\
\hline $1 y$ & 29 & $98.1(14.3)$ & 23 & $100.9(7.9)$ & -3.9 & 9.5 & 0.40 & 37 & $87.6(12.7)$ & 35 & $97.3(9.4)$ & 4.4 & 15.0 & $<0.001$ \\
\hline $2 y$ & 28 & $100.4(16.7)$ & 21 & $102.0(11.8)$ & -7.0 & 10.3 & 0.70 & 37 & $88.6(15.2)$ & 34 & $101.5(10.1)$ & 6.7 & 19.1 & $<0.001$ \\
\hline $3 y$ & 29 & $100.0(12.8)$ & 23 & $102.0(7.8)$ & -4.1 & 8.1 & 0.50 & 40 & $92.3(11.4)$ & 34 & $102.6(11.6)$ & 5.0 & 15.7 & $<0.001$ \\
\hline $4 \frac{1}{2} y$ & 29 & $107.3(15.1)$ & 23 & $114.3(12.7)$ & -1.0 & 14.8 & 0.09 & 42 & $98.9(14.3)$ & 31 & $114.3(11.8)$ & 9.2 & 21.7 & $<0.001 * *$ \\
\hline $81 \frac{1}{2} y$ & 24 & $96.6(17.6)$ & 19 & $119.8(13.3)$ & 13.4 & 33.1 & $<0.001 \dagger$ & 31 & $98.9(14.8)$ & 29 & $113.7(14.4)$ & 7.3 & 22.4 & $<0.001^{*}$ \\
\hline
\end{tabular}

The children's general cognitive abilities at 1,2, and 3 y of age were assessed using the Bayley-II Mental Development Index; at 4⿳⺈/2 y using the McCarthy General Cognitive Index; and at $81 / 2$ y using the Wechsler Intelligence Scale for Children - Revised Total IQ.

$P$ values are exact $P$ values for bivariate $t$-test. Asterisk are $P$ values based on multiple mixed effects models including the interaction effect between group and time, and controlled for socioeconomic status, gestational age and birth weight.

*Multiple $P \leq 0.05$; ${ }^{* *}$ Multiple $P \leq 0.01$; † Multiple $P \leq 0.001$. 
gestational age, and birth weight, and included the interaction effect between time and group. The total interaction effect of time ${ }^{\star}$ group for the whole sample was significant $(F(4)=2.76$, $P=0.03$ ). The difference in cognitive scores between the groups at $8 \frac{1}{2}$ y was significantly greater than the differences between the groups at $1 \mathrm{y}(B=0.52,95 \%$ CI $0.13-0.91, P=0.009), 2 \mathrm{y}$ $(B=0.54,95 \%$ CI $0.15-0.94, P=0.007)$ and $3 y(B=0.48,95 \%$ CI $0.10-0.87, P=0.01)$. Neither the increase in difference from 3 to $4 \frac{1}{2}$ y $(B=0.23,95 \%$ CI -0.16 to $0.63, P=0.24)$ nor the increase in difference from $4 \frac{1}{2}$ until $8 \frac{1}{2} 2$ y $(B=0.25,95 \% \mathrm{CI}$ -0.14 to $0.64, P=0.21$ ) was significant.

The increased difference over time between the groups was mainly explained by changes among the girls (Figure 1). Thus, when redoing the mixed effects analyses separately for boys and girls, we found no group ${ }^{\star}$ time effect for boys $(F(4)=0.40$, $P=0.81)$. However, for the girls, the effect of group ${ }^{\star}$ time was highly significant $(F(4)=4.14, P=0.003)$ with differences in cognitive scores between the exposed group and the control group at $8 \frac{1}{2}$ y being significantly $(P<0.01)$ higher than at all earlier times.

Results similar to those of the total sample were found when rerunning the analyses for the combined subsample of children who moved to permanent foster- or adoptive parents and who had mothers who had heroin as their main drug of choice during pregnancy $(n=30)$. They had significantly lower cognitive abilities than the control group $(n=58)$ at all time points except at 1 y of age (Diff ${ }_{1 \mathrm{y}}=4.7,95 \% \mathrm{CI}-0.2$ to $9.6, P=0.06$; Diff $_{2 y}=6.5,95 \%$ CI $0.5-12.5, P=0.03$; Diff $_{3 y}=5.4,95 \% \mathrm{CI}$ $0.4-10.4, P=0.04$; Diff ${ }_{4 \frac{1}{2} \mathrm{y}}=10.7,95 \%$ CI 4.8-16.5, $P<0.001$; Diff $_{8 \frac{1}{2} y}=20.6,95 \%$ CI 14.3-27.0, $\left.P<0.001\right)$. The interaction effect between time and group was significant $(F(4)=5.0$, $P=0.001)$ with difference in cognitive scores between the groups significantly greater $(P \leq 0.05)$ at $8 \frac{1}{2}$ y than at $1,2,3$, and $4 \frac{1}{2} \mathrm{y}$ of age, while the increase in differences from 3 to $4 \frac{1}{2}$ y was not significant $(P=0.09)$. As in the analyses for the whole sample, the group differences for the girls were significantly higher at $8 \frac{1}{2} \mathrm{y}$ than at any of the previous assessments, whereas there were no significant changes over time in group differences for the boys.

\section{Predictors of Cognitive Abilities at Age $81 / 2$ y}

To investigate whether the group difference in cognitive scores at $8 \frac{1}{2}$ y was related to earlier cognitive scores or to a continuous effect over time independent of earlier cognitive scores, multiple regression analyses were performed (Table 2). Children in the exposed group had significantly lower cognitive abilities at $8 \frac{1}{2}$ y than those in the control group even after controlling for earlier cognitive abilities. Thus, the effect of the group remained significant regardless of gestational age, birth weight and earlier cognitive abilities.

Also the multiple regression analyses were rerun excluding children who had not moved to stable foster/adoption homes at $1 \mathrm{y}$ or who had mothers whose main drug during pregnancy was something other than heroin (Supplementary Table S1 online). Similar results were found for this subsample as for the total sample (Table 2). Furthermore, the group effect in the final model $(B=17.04,95 \%$ CI 8.69-25.38, $P<0.001)$ was quite similar to the differences between the groups before taking into account any other covariates $(B=20.94,95 \% \mathrm{CI}$ 14.27-27.61, $P<0.001)$.

\section{DISCUSSION}

The main findings of this study were: (i) The difference in cognitive abilities between drug-exposed and nonexposed children was not reduced over time, and lower functioning emerged later for the girls in the exposed group. (ii) The group difference in cognitive abilities at $8 \frac{1}{2}$ y was also highly significant when taking into account earlier cognitive abilities. These findings indicate continuous negative processes in children born to mothers with opioid and polysubstance abuse.

Table 2. Bivariate and multiple regression $(95 \% \mathrm{Cl})$ for predicting cognitive abilities at $8 \frac{1}{2}$ y $(\mathrm{IQ})(n=130)$

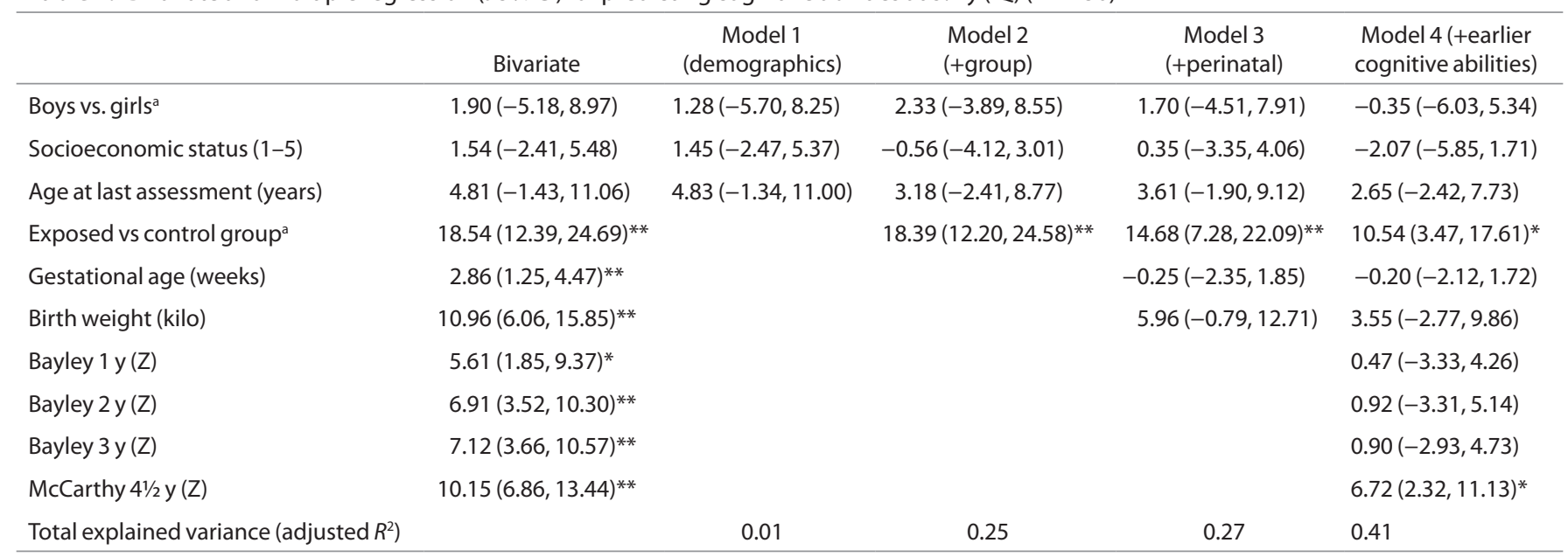

Earlier cognitive abilities (Bayley Mental Developmental Index at 1, 2, and 3 y; McCarthy General Cognitive Index at 4\%1/2y) were standardized ( $Z$-values) before being entered into the models. All models used multiple imputed data to avoid loss of information. Values are regression coefficient (B) with $95 \%$ confidence intervals in parentheses. The explained variance in the total model without group as a predictor was 0.36 .

aBoys and prenatally exposed children were set to zero in the regression analyses.

${ }^{*} P \leq 0.01 ;{ }^{* *} P \leq 0.001$. 
While this is a naturalistic study that cannot isolate the effect of prenatal drug exposure, it should be noted that similar results were found for the complete sample and for the sub-sample of children who moved to stable foster/adoption homes before 1 $y$ of age and whose mothers used heroin as their main choice of drug.

Due to the lack of knowledge of possible confounding variables, it is impossible to know why the opioid and polysubstance-exposed boys, but not girls had lower cognitive abilities up to $3 \mathrm{y}$ of age in the present study. Boys may be more vulnerable than females to possible prenatal neurotoxins drug exposure (22). Previous findings also suggest that infant boys often need more coregulation than girls (30). There is a marked male preponderance for almost all neurodevelopmental disorders that arise before school age, including attention-deficit disorder with hyperactivity (31), and for example DelanayBlack et al. (23) found 6-y-old cocaine-exposed boys, but not girls, to show more hyperactivity and cognitive problems than nonexposed. Normal sex differences and a less optimal male prenatal starting point may interact with neonatal abstinences and increased regulation problems often found among drugexposed children (2).

The causal mechanisms of the declining trajectory of the opioid and polysubstance exposed girls between $4 \frac{1}{2}$ and $8 \frac{1}{2}$ y are unknown. One possible explanation for the problems at $81 / 2$ $\mathrm{y}$ is that earlier cognitive problems may influence later cognitive abilities. Thus, the effect of prenatal risk factors on cognitive abilities at $81 / 2$ y may be mediated through earlier effects on cognitive abilities. This was partly supported in that cognitive abilities at $4 \frac{1}{2} \mathrm{y}$ were a significant positive predictor of cognitive abilities at $8^{1 / 2} \mathrm{y}$ in the final multiple regression analyses. However, the results also indicated that group belonging predicted cognitive abilities at $8^{1 / 2}$ y even after controlling for earlier cognitive abilities. Thus, there seems to be a deceleration of positive development, or there may be additional causal paths between the age of $4 \frac{1}{2} \mathrm{y}$ and $81 / 2$ y than those already influencing cognitive abilities at $4 \frac{1}{2} \mathrm{y}$.

It is probable that pre- and postnatal genetic vulnerabilities and environmental factors interact in a transactional way through the child's life (32). Thus, biological constitution, including genetic makeup, nutrition, and drug exposure, may interact with later environmental factors, such as parental caregiving, quality of day care and school, in influencing the cognitive development of the child. Thus, a possible explanation is that these drug-exposed girls may have profited early on from a stable placement with specially selected foster/adoptive parents. When entering preschool and school, however, they face a more complex and less protective social environment with increasingly higher demands that challenge their vulnerability. For example, some studies report specific attention problems of opioid-exposed children that may influence their behavior and emotional regulation (33). It is also possible that drug-exposed children are more vulnerable to later environmental risk factors as was for example found by Yumoto et al. (34). Girls' general preponderance for emotional problems arising in adolescence (31) may also begin to interact with the vulnerability of the exposed girls at an even earlier age. Unfortunately, we do not have enough information in the present clinical study to investigate such complex models of the children's development.

A limitation of the study is the low number of participants, minimizing the possibility to control the results of covariate factors. Additionally, it is difficult to measure complex cognitive abilities in infancy, and the Bayley Scales have relatively low predictive validity of later cognitive abilities (35). The increase in group difference over time may thus relate to increased validity of the tests as the children get older. However, the stable male difference between groups indicates that the increase in group differences in girls' cognitive abilities was not due to the aforementioned methodological issues. Only parentrelated variables, such as moving to stable caregivers before $1 \mathrm{y}$ of age, differed between participants and drop outs at $8 \frac{1}{2} \mathrm{y}$. The sub-analyses including only participants who moved to stable caregivers before the first assessment gave similar results, thus drop out does not seem to have influenced the results in any substantial way.

The present study cannot isolate the effects of drug exposure in utero, and the differences between the groups may, in addition to the drug exposure, be influenced by other factors, such as heredity, which cannot be controlled for, and detrimental experiences before moving to final caregivers. However, the early age of placement and intense follow-up by the perinatal risk project team before moving should have minimized the effect of an early detrimental environment. The care given by adoptive/foster parents may differ from the care given by biological parents, and it is a limitation that the present study did not include a comparison group of adopted/foster children without prenatal drug exposure. However, the adoptive and foster parents in the present study were stable, and specially selected for caring for children at risk and they had relatively high SES compared to what was common for foster parents and the population in general in Norway $(20,36)$. Thus, there are indications that the children who moved to foster/adoptive parents were brought up in normal and stable caring family environments.

\section{Conclusion}

The results indicate that foster-and adoptive children exposed to opioid and polysubstance abuse in utero do not cognitively "catch-up" over time, even when placed in low-risk stable families at a very early age. Rather, vulnerabilities appear to increase with age for girls, and the exposed boys remain behind nonexposed boys all through infancy and into school age. Thus, there seems to be a continuous negative effect of factors related to prenatal drug exposure over time. It is important to investigate how prenatal risk factors interact with other risk factors as children grow older.

\section{METHODS}

\section{Participants}

The initial sample was composed of 78 children exposed to opioids and other substances in utero and 58 nonexposed children. The initial sample, measures and test results at $1,2,3$, and $4 \frac{1}{2} \mathrm{y}$ have previously 
Table 3. Characteristics of initial sample divided by group

\begin{tabular}{|c|c|c|c|c|c|c|c|}
\hline & \multicolumn{2}{|c|}{ Exposed group $(n=72)$} & \multicolumn{2}{|c|}{ Control group $(n=58)$} & \multicolumn{3}{|c|}{ Difference } \\
\hline & \multirow[b]{2}{*}{ Mean (SD) } & \multirow[b]{2}{*}{ Range } & \multirow[b]{2}{*}{ Mean (SD) } & \multirow[b]{2}{*}{ Range } & \multicolumn{2}{|c|}{$95 \% \mathrm{Cl}$} & \multirow[b]{2}{*}{$P$} \\
\hline & & & & & Lower & Upper & \\
\hline Gestational age (weeks) & $38.6(2.1)$ & $31.0-42.0$ & $40.4(1.4)$ & $35.0-42.5$ & 1.3 & 2.5 & $<0.001$ \\
\hline Birth weight (kilo) & $3.070(0.643)$ & $1.160-4.380$ & $3.707(0.455)$ & $2.620-4.615$ & 0.439 & 0.835 & $<0.001$ \\
\hline Birth head circumference $(\mathrm{cm})$ & $34.1(1.7)$ & $28.0-37.5$ & $35.6(1.2)$ & $32.0-38.0$ & 1.0 & 2.1 & $<0.001$ \\
\hline Socioeconomic status & $3.4(0.9)$ & $1.0-5.0$ & $3.8(0.9)$ & $1.5-5.0$ & 0.0 & 0.7 & 0.03 \\
\hline Age at last assessment (years) ${ }^{\mathrm{a}}$ & $8.7(0.7)$ & $6.7-10.0$ & $8.8(0.4)$ & $7.9-9.6$ & -0.1 & 0.3 & 0.28 \\
\hline
\end{tabular}

Socioeconomic status was measured on a five-point scale based on both parents' education and occupation with 1 indicating unskilled worker with only compulsory education and 5 indicating a parent with a profession requiring at least a bachelor's level education.

${ }^{a} n=55$ children in the opioid and polysubstance-exposed group and 48 children in the control group.

been described in detail $(20,21,37)$. The drug-exposed children were recruited from Aline Infant and Family Center in Oslo where they were enrolled in a perinatal risk project during the period 1992-1996. The center is a social service institution for families with children 0-2 $y$ of age. The majority $(76.9 \%)$ was enrolled in the perinatal risk project by the second or third trimester of pregnancy, and the rest were enrolled in the risk project after birth. Because one of the aims of the study was to assess child outcome under conditions of adequate care, the comparison children were recruited from a nonclinical setting of local maternal and child health centers in Norway were biomedical vulnerability and social risk factors were minimal.

In the present analyses, six children who had fetal alcohol syndrome or fetal alcohol spectrum disorder as documented during the first year of life were excluded. Thus, the total number of participants included is 72 opioid and polysubstance-exposed (30 girls, 42\%) and 58 comparison ( 23 girls, $40 \%$ ) children. Number of participants differed across time points, with $124,120,126,125$, and 103 children at $1,2,3,4 \frac{1}{2}$, and $8 \frac{1}{2}$ y of age respectively.

Whereas all children in the control group lived with their biological families throughout the study period, most children in the exposed group were either adopted or moved to permanent foster homes before the age of 1 y $(n=52 / 72,72 \%)$. The County Social Welfare Board made the decision concerning custody of the child after the child protection services had evaluated the mothers' ability to participate in a rehabilitation program for drug and alcohol addiction, and to adequately care for their children. Five children in the exposed group still lived with a biological parent at the time of the last assessment.

Information concerning prenatal exposure was gathered by a combination of interview with the biological mothers and information from their medical and social records (20). The biological mothers of the children in the substance-exposed group used a wide range of drugs. The most common main drug of choice was opioids (heroin) $(n=39$, $54 \%)$, followed by benzodiazepines $(n=9,13 \%)$ and alcohol $(n=8$, $11 \%)$. They had, on average, used 3.3 different drugs, including tobacco, during pregnancy (range $2-6)$. Most of the exposed children $(n=57 / 72$, $79 \%$ ) had neonatal abstinences as recorded from the children's medical records. None of the children in the control group and $16(22 \%)$ of the children in the exposed group had low birth weight $(<2,500 \mathrm{~g})$. See Table 3 for further information about the sample and Supplementary Methods online and Supplementary Table S2 online about their polydrug exposure.

Children who participated at $81 / 2$ y were more often placed in permanent foster or adoptive homes before the age of 1 y ( $82 \mathrm{vs.} 47 \%, \chi^{2}$ $(1)=8.08, P=0.004)$ than children who did not participate at $81 \frac{1}{2}$ y of age. No other differences were found between participants and nonparticipants at the last assessment (Supplementary Table S3 online).

\section{Procedure}

The assessments of the substance-exposed group were sometimes used as the basis for reports and clinical suggestions in collaboration with supportive intervention for the children and their families at the Aline Infant and Family Center. Thus, the assessments were not blind. Efforts were made to adhere to strict standardized testing procedures. The assessments at $1,2,3$, and $4 \frac{1}{2}$ y were conducted by two of the coauthors (K.S. and V.M.). The assessment at $81 \frac{1}{2}$ y was conducted by three graduate students of clinical psychology in their last year of education and under the supervision of the coauthors. Written informed consent was obtained from parents and foster/adoptive parents of all children. The study was approved by the Regional Ethical Committee.

\section{Measures}

Perinatal information about the children was gathered from each child's medical record. Parental SES was measured on a five-point scale based on caregivers' education and occupation with 1 indicating unskilled worker with only compulsory education and 5 indicating a caregiver with a profession requiring at least a bachelor's level education (20).

The children's cognitive abilities were tested using the Mental Development Index of the Bayley-II Scales of Infant Development (38) at 1,2 , and $3 y$ of age. The raw scores were converted to index scores (expected mean $=100, \mathrm{SD}=15)$ according to US norms. At age $4 \frac{1}{2}$, the McCarthy Scales of Children's Abilities (39) was used. The raw scores were converted to General Cognitive Index scores (expected mean $=100, \mathrm{SD}=16$ ) according to US norms. The Wechsler Intelligence Scale for Children-Revised (40) was used at $81 / 2$ y of age. The raw scores based on ten different subtests were transformed into a total IQ score (expected mean $=100, S D=15)$ based on Norwegian norms. See also Supplementary Methods online concerning the cognitive assessments.

\section{Statistics}

Student's $t$-tests were used to analyze group differences at each time point. Mixed effects models were used to analyze the effect of time on the difference in cognitive scores between the exposed and the control groups. Different tests of cognitive abilities with different normative data were used over time. The tests were some of the most commonly used for measuring general cognitive abilities. However, due to differences in standardization, the normed scores from the cognitive tests were converted to $Z$-values (mean $=0, S D=1$ ) calculated separately at each assessment point before being entered into the model. Due to possible gender differences (20), the analyses are replicated separately for girls and boys. See Supplementary Methods online for further information about the mixed effects models.

Multiple linear regression analyses were used to investigate whether cognitive abilities at $8^{1 / 2}$ y of age were related to group differences when controlled for earlier cognitive abilities. The independent variables for demographics, group, perinatal factors, and earlier cognitive abilities (at $1,2,3$, and $4 \frac{1}{2} \mathrm{y}$ ) were entered one at a time, each model including previous variables. This procedure takes into account both predictors of cognitive function at the last assessment, and possible further changes independent of earlier cognitive function. Due to missing cognitive data, the regression analyses were based on multiple (200) imputations using the fully conditional specification method.

Both the mixed effects models and the multiple linear regression analysis were rerun on a subsample $(n=30)$ including only children who were permanently placed in adoptive/foster homes before $1 \mathrm{y}$ of age and whose mothers used heroin as their main drug during pregnancy in the risk group. 
Demographics (sex, SES, and age at time of last assessment) and perinatal factors (gestational age and birth weight) were controlled for in all mixed effects and multiple linear models. All analyses were performed with IBM SPSS version 20 and used a 95\% confidence level.

\section{SUPPLEMENTARY MATERIAL}

Supplementary material is linked to the online version of the paper at http://www.nature.com/pr

\section{ACKNOWLEDGMENT}

We thank Tore Wentzel-Larsen for statistical advice.

\section{STATEMENT OF FINANCIAL SUPPORT}

The study was supported by Norwegian Research Council, grants 190411 and 213762 .

Disclosure: The authors do not have any financial or other conflicts of interest to disclose.

\section{REFERENCES}

1. Moe V, Siqveland T, Slinning K. Children of parents with substance abuse and mental health problems. In: FitzGerald HE, Puura K, Tomlinson M, Paul C, eds. International Perspectives on Children and Mental Health, Vols 1 and 2: Development and context, Prevention and Treatment. Santa Barbara, CA: Praeger/ABC-CLIO, 2011. pp. 155-77.

2. Lester BM, Lagasse LL. Children of addicted women. J Addict Dis 2010;29:259-76.

3. Ornoy A, Daka L, Goldzweig G, et al. Neurodevelopmental and psychological assessment of adolescents born to drug-addicted parents: effects of SES and adoption. Child Abuse Negl 2010;34:354-68.

4. Hunt RW, Tzioumi D, Collins E, Jeffery HE. Adverse neurodevelopmental outcome of infants exposed to opiate in-utero. Early Hum Dev 2008;84: 29-35.

5. Patrick SW, Schumacher RE, Benneyworth BD, Krans EE, McAllister JM, Davis MM. Neonatal abstinence syndrome and associated health care expenditures: United States, 2000-2009. JAMA 2012;307:1934-40.

6. Manchikanti L, Fellows B, Ailinani H, Pampati V. Therapeutic use, abuse, and nonmedical use of opioids: a ten-year perspective. Pain Physician 2010;13:401-35.

7. World Health Organization. Guidelines for the Psychosocially Assisted Pharmacological Treatment of Opioid Dependence. Geneva, 2009.

8. Ackerman JP, Riggins T, Black MM. A review of the effects of prenatal cocaine exposure among school-aged children. Pediatrics 2010;125: $554-65$.

9. Bauer CR, Shankaran S, Bada HS, et al. The Maternal Lifestyle Study: drug exposure during pregnancy and short-term maternal outcomes. Am J Obstet Gynecol 2002;186:487-95.

10. Logan BA, Brown MS, Hayes MJ. Neonatal abstinence syndrome: treatment and pediatric outcomes. Clin Obstet Gynecol 2013;56:186-92.

11. Walhovd KB, Moe V, Slinning K, et al. Volumetric cerebral characteristics of children exposed to opiates and other substances in utero. Neuroimage 2007;36:1331-44.

12. Walhovd KB, Watts R, Amlien I, Woodward LJ. Neural tract development of infants born to methadone-maintained mothers. Pediatr Neurol 2012;47:1-6.

13. Walhovd KB, Westlye LT, Moe V, et al. White matter characteristics and cognition in prenatally opiate- and polysubstance-exposed children: a diffusion tensor imaging study. AJNR Am J Neuroradiol 2010;31:894-900.

14. Yuan Q, Rubic M, Seah J, et al.; BOB (Brains, Opioids and Babies) Collaborative group. Do maternal opioids reduce neonatal regional brain volumes? A pilot study. J Perinatol 2014;34:909-13.

15. Harlan RE, Song DD. Prenatal morphine treatment and the development of the striatum. Regul Pept 1994;54:117-8.

16. Wang Y, Han TZ. Prenatal exposure to heroin in mice elicits memory deficits that can be attributed to neuronal apoptosis. Neuroscience 2009;160:330-8.

17. Lu R, Liu X, Long H, Ma L. Effects of prenatal cocaine and heroin exposure on neuronal dendrite morphogenesis and spatial recognition memory in mice. Neurosci Lett 2012;522:128-33.
18. Konijnenberg C, Melinder A. Prenatal exposure to methadone and buprenorphine: a review of the potential effects on cognitive development. Child Neuropsychol 2011;17:495-519.

19. Messinger DS, Bauer CR, Das A, et al. The maternal lifestyle study: cognitive, motor, and behavioral outcomes of cocaine-exposed and opiateexposed infants through three years of age. Pediatrics 2004;113:1677-85.

20. Moe V, Slinning K. Children prenatally exposed to substances: Genderrelated differences in outcome from infancy to 3 years of age. Inf Mental Hlth J 2001;22:334-50.

21. Slinning K. Foster placed children prenatally exposed to poly-substancesattention-related problems at ages 2 and $4 \frac{1}{2}$. Eur Child Adolesc Psychiatry 2004;13:19-27.

22. Lewis M, Kestler L. Gender differences in prenatal substance exposure. Washington DC: American Psychological Association, 2012.

23. Delaney-Black V, Covington C, Nordstrom B, et al. Prenatal cocaine: quantity of exposure and gender moderation. J Dev Behav Pediatr 2004;25:254-63.

24. Crea TM, Barth RP, Guo S, Brooks D. Behavioral outcomes for substanceexposed adopted children: fourteen years postadoption. Am J Orthopsychiatry 2008;78:11-9.

25. Mayes LC. Developing brain and in utero cocaine exposure: effects on neural ontogeny. Dev Psychopathol 1999;11:685-714.

26. van Baar A, de Graaff BM. Cognitive development at preschool-age of infants of drug-dependent mothers. Dev Med Child Neurol 1994;36: 1063-75.

27. Hans SL, Jeremy RJ. Postneonatal mental and motor development of infants exposed in utero to opioid drugs. Inf Mental Hlth J 2001;22:300-15.

28. Strauss ME, Starr RH, Ostrea EM, Chavez CJ, Stryker JC. Behavioural concomitants of prenatal addiction to narcotics. J Pediatr 1976;89:842-6.

29. Delano K, Gareri J, Koren G. Rates of fetal polydrug exposures in methadone-maintained pregnancies from a high-risk population. PLoS One 2013;8:e82647.

30. Weinberg MK, Tronick EZ, Cohn JF, Olson KL. Gender differences in emotional expressivity and self-regulation during early infancy. Dev Psychol 1999;35:175-88.

31. Rutter M. Multiple meanings of a developmental perspective on psychopathology. Eur J Dev Psychol 2005;2:221-52.

32. Sameroff A. A unified theory of development: a dialectic integration of nature and nurture. Child Dev 2010;81:6-22.

33. Melinder A, Konijnenberg C, Sarfi M. Deviant smooth pursuit in preschool children exposed prenatally to methadone or buprenorphine and tobacco affects integrative visuomotor capabilities. Addiction 2013;108:2175-82.

34. Yumoto C, Jacobson SW, Jacobson JL. Fetal substance exposure and cumulative environmental risk in an African American cohort. Child Dev 2008;79:1761-76.

35. Sergeant J, Taylor E. Psychological testing and observation. In: Rutter M, Taylor E, eds. Child and Adolescent Psychiatry. Oxford: Blackwell Publising Ltd, 2002.

36. Statistics Norway. Education level in the population. 2013. (http://www. ssb.no/utniv/tab-2012-06-19-01.html.). Accessed 15 October 2014

37. Moe V. Foster-placed and adopted children exposed in utero to opiates and other substances: prediction and outcome at four and a half years. J Dev Behav Pediatr 2002;23:330-9.

38. Bayley N. Bayley Scales of Infant Development. 2nd edn. New York: The Psychological Corporation, 1993.

39. McCarthy D. Manual for the McCarthy Scales of Children's Abilities. New York: The Psychological Corporation, 1972

40. Wechsler D. Handbook for Wechsler Intelligence Scale for Children - Revised New York: The Psychological Corporation, 1974.

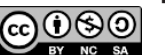

This work is licensed under a Creative Commons Attribution-NonCommercial-ShareAlike 4.0 International License. The images or other third party material in this article are included in the article's Creative Commons license, unless indicated otherwise in the credit line; if the material is not included under the Creative Commons license, users will need to obtain permission from the license holder to reproduce the material. To view a copy of this license, visit http://creativecommons.org/ licenses/by-nc-sa/4.0/ 